\title{
Outbreak of Mycoplasma pneumoniae at a military academy
}

\author{
Xin Zhang ${ }^{1+}$, Min-Na Han ${ }^{2+}$, Jing-Hui Dong ${ }^{3}$, Xiao-Xi Li ${ }^{4}$, Xian-Yun Hu${ }^{2}$, Zhi Wang ${ }^{2}$, En-Qiang Qin ${ }^{1}$, Jing Li', \\ Jun-Yuan Tan ${ }^{5}$, Fu-Sheng Wang ${ }^{1 *}$ and Lei Huang ${ }^{1 *}$
}

\begin{abstract}
In 2019, an outbreak of Mycoplasma pneumoniae occurred at a military academy in China. The attack rate (10.08\%, 60/595) was significantly different among the units. High-intensity training and crowded environments to which cadets are exposed are the high risk factors for the outbreak of M. pneumoniae. In-time prevention and control measures effectively controlled the spread of the epidemic.
\end{abstract}

Keywords: Mycoplasma pneumoniae, Epidemiological survey, Disease control and prevention

Dear editor,

Mycoplasma pneumoniae may be the causative agent of $70 \%$ in crowded populations such as military personnel and students [1]. In the winter of 2019, a M. pneumoniae outbreak occurred at a military academy in China. Here we report the result of epidemiological investigation and disease prevention/ control measures.

The outbreak occurred among training freshmen, the barracks were devoid of heating equipment, with residence area of $2.8-3.2 \mathrm{~m}^{2}$ per capita. All cadets ate at one cafeteria. Since late November 2019, total 15 cadets developed cold-like symptoms, all of them tested positive for M. pneumoniae IgM antibody, and several had CT scan-confirmed pneumonia. As the outbreak continued to spread, the patients were isolated in a temporary ward in early December. As strict prevention and control measures were timely implemented, new cases quickly declined, and the last case was reported on January 1 st 2020.

\footnotetext{
*Correspondence: fswang302@163.com; huangleiwa@sina.com

${ }^{+}$Xin Zhang and Min-Na Han contributed equally to this work.

${ }^{1}$ Center for Infectious Disease, the Fifth Medical Center of Chinese PLA General Hospital, Beijing 100039, China

Full list of author information is available at the end of the article
}

The attack rate was $10.08 \%$ (60/595), with a total of 36 confirmed cases and 24 suspected cases (case definition see Additional file: Appendix I). The outbreak lasted 102 days, with four peaks. The interval between each peak was nearly the incubation period (Fig. 1).

The 60 cases were distributed among five companies: 12 in company G, 10 in company H, 17 in company I, four in company $\mathrm{J}$, and 17 in company $\mathrm{K}$. The highest attack rate was in company $\mathrm{K}(17 / 110,15.45 \%)$ and the lowest in company J (4/118, 3.39\%). There were significant differences in attack rate between companies $\mathrm{H}$ and $\mathrm{K}$ $\left(\mathrm{X}^{2}=3.515, p=0.048\right), \mathrm{G}$ and $\mathrm{J}\left(\mathrm{X}^{2}=3.871, p=0.042\right), \mathrm{I}$ and $J\left(X^{2}=9.351, p=0.002\right)$, and $J$ and $K\left(X^{2}=9.910\right.$, $p=0.001$; Additional file: Appendix Table S1 and Appendix Figure S1).

We obtained complete medical records for 33 cases, including 19 confirmed and 14 suspected cases. The most common symptoms were cough (30/33) and fever (27/33). Other symptoms included runny nose (27, 81.82\%), rhinobyon $(23,69.70 \%)$, sore throat $(22,66.67 \%)$, sneezing (21, 63.64\%), fatigue (21, 63.64\%) and headache (18, 54.55\%). Sixteen cases had a history of burnout (e.g., stay up late or night shifts).

Within the 36 cases that tested positive for IgM antibody. Thirty-three of the patients had a chest computed tomography $(\mathrm{CT})$ scan and 21 of the patients had 


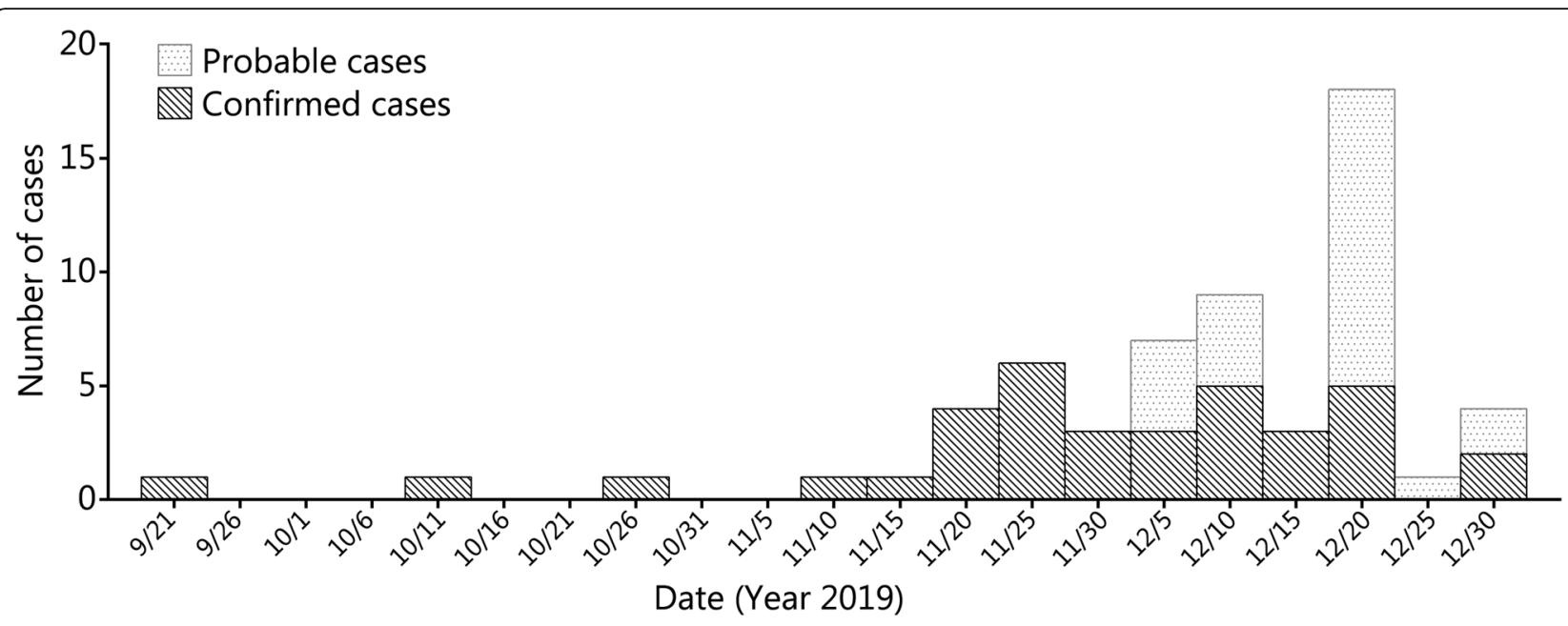

Fig. 1 Number of confirmed cases every 5 days

radiologically confirmed pneumonia. The main damages were consolidation in 8 cases, ground glass opacity in 8 cases and fibrosis formation in 2 cases. Details see Additional file: Appendix Figure S1.

All confirmed and suspected cases were treated with moxifloxacin or levofloxacin for 10 to 14 days. Two severe cases were hospitalized for 7 to 10 days. All patients were successfully treated without any complications or sequela.

Following the incidence of febrile patients, an emergency response team was immediately organized. The prevention and control measures were the following. (1) Isolation: all patients were isolated in a temporary ward, and all group activities were canceled. (2) Quarantine: all close contacts were quarantined. (3) Daily morning health check for any symptoms of disease. (4) Daily "zero" reporting system. (5) Sterilization and disinfection, especially in dormitories, bathrooms, and cafeteria. (6) Health education: wear face masks, improve hand hygiene and cough manners (cover mouth and nose with elbow or tissue instead of hands). Following a maximum incubation period with no registered new cases, the outbreak was declared terminated.

Clinical manifestations of $M$. pneumoniae infections are variable. The most common manifestation is tracheobronchitis. Most of patients report non-specific symptoms similar to those of the common cold or other upper respiratory infections (URI). It is a challenge to effectively distinguish $M$. pneumoniae pneumonia from pneumonia caused by other pathogens based on clinical manifestations or imaging results [2]. Currently, the most common clinical tests are based on serology and nucleic acid detection. The titer of IgM antibody reaches a detectable level within 1 week after disease onset, and the sensitivity is low, limiting the clinical value of these tests in early diagnosis [3].
Currently, macrolides are the preferred first-line antibiotics for M. pneumoniae infections. However, surveillance of antibiotic resistance by Chinese CDC showed that the prevalence of macrolide-resistant M. pneumoniae (MRMP) was $98.1 \%$ in children under 14 years of age and $83 \%$ in adolescents and adults [4]. Respiratory fluoroquinolones can achieve high concentrations in lung tissue and have greater activity than macrolides.

This outbreak in Northern China lasted more than 3 months. The time interval between each peak, which was approximately an incubation period, showed the typical features of generation to generation transmission. The possible reasons for this outbreak may be explained as follows, 1) high-intensity training and psychological stress decreases immunity and 2) cold and dry climates, high-density residences, and non-ventilated rooms promote the epidemic spread.

In summary, accurate etiological diagnosis, early isolation, standardized treatment of patients, medical observation, quarantine of close contacts, and regular environmental disinfection are crucial measures to reduce secondary transmission and mitigate outbreak consequences.

\section{Supplementary Information}

The online version contains supplementary material available at https://doi. org/10.1186/s40779-020-00289-x.

\section{Additional file.}

\section{Abbreviations}

CAP: Community-acquired pneumonia; CT: Computed tomography;

URI: Upper respiratory infections; MRMP: Macrolide-resistant M. pneumoniae

\section{Acknowledgements}

We are grateful to Bo-An Li and Bo Li from the 5th medical center for their contribution in immunological tests. 


\section{Authors' contributions}

$\mathrm{XZ}, \mathrm{MNH}, \mathrm{LH}$, and FSW designed the study and wrote the manuscript, had full access to the data, and take responsibility for the accuracy of the data analysis; XZ, MNH, JHD, EQQ, JYT, and XXL analyzed data; $M N H, X Y H, Z W$, EQQ collected samples, clinical data, and contributed to the manuscript preparation; JHD analyzed the $C T$ images and drafted the manuscript; $J L$ and EQQ made critical revisions to the manuscript; LH obtained funding sources for this study; XYH, ZW, JL, and JYT provided administrative, technical, and/or logistic support for the study. All authors have contributed to, read, and approved the final, submitted version of the manuscript.

\section{Funding}

This study was supported by the military medical innovation research project of PLAGH (CX19015) and program for military medical innovation (18CXZ038).

\section{Availability of data and materials}

All data generated or analyzed during this study are included in this published manuscript.

\section{Ethics approval and consent to participate}

Written informed consent was obtained from each participant.

\section{Consent for publication}

Not applicable.

\section{Competing interests}

None of the authors have any competing interests in the manuscript.

\section{Author details}

${ }^{1}$ Center for Infectious Disease, the Fifth Medical Center of Chinese PLA General Hospital, Beijing 100039, China. ${ }^{2}$ Southern Distract Health Service of Chinese PLA General Hospital, Beijing 100039, China. ${ }^{3}$ Radiology Department, the Fifth Medical Center of Chinese PLA General Hospital, Beijing 100039, China. ${ }^{4}$ Clinical Lab Center, the Fifth Medical Center of Chinese PLA General Hospital, Beijing 100039, China. ${ }^{5}$ Medical Service Department, the Fifth Medical Center of Chinese PLA General Hospital, Beijing 100039, China.

Received: 16 September 2020 Accepted: 11 November 2020

Published online: 03 December 2020

\section{References}

1. Jacobs E, Ehrhardt I, Dumke R. New insights in the outbreak pattern of mycoplasma pneumoniae. Int J Med Microbiol. 2015;305(7):705-8. https://doi.org/10.1016/j.jmm.2015.08.021.

2. Miyashita N, Akaike H, Teranishi H, Nakano T, Ouchi K, Okimoto. NChest computed tomography for the diagnosis of Mycoplasma pneumoniae infection [J]. Respirology. 2014;19(1):144-5. https://doi.org/10.1111/resp. 12218.

3. Waites KB, Talkington DF. Mycoplasma pneumoniae and its role as a human pathogen [J]. Clin Microbiol Rev. 2004;17(4):697-728. https://doi.org/10. 1128/CMR.17.4.697-728.2004

4. Zhao F, Liu G, Wu J, Cao B, Tao XX, He LH, et al. Surveillance of macrolideresistant Mycoplasma pneumoniae in Beijing, China, from 2008 to 2012[J]. Antimicrob Agents Chemother. 2013; 57(3):1521-3. https://doi.org/10.1128/ AAC.02060-12.

Ready to submit your research? Choose BMC and benefit from:
- fast, convenient online submission
- thorough peer review by experienced researchers in your field
- rapid publication on acceptance
- support for research data, including large and complex data types
- gold Open Access which fosters wider collaboration and increased citations
- maximum visibility for your research: over 100M website views per year
At BMC, research is always in progress.
Learn more biomedcentral.com/submissions

